\title{
Diamond Blackfan Anemia A Rare Anemia of Infancy
}

\author{
SABINA SULTANA ${ }^{1}$, SARWAR FERDOUS ${ }^{2}$, NURUL HOSSAIN ${ }^{1}$, MD. SALAHUDDIN SHAH ${ }^{3}$, MRINAL \\ KANTI DAS ${ }^{4}$, ASMAFERDOUS ${ }^{5}$
}

\begin{abstract}
Introduction
Diamond Blackfan anemia (DBA) is a rare anemia characterized by failure of erythropoisis, with normal production of white blood cell and platelets.

Children with anemia without pancytopenia were first described in 1936 and again in 1938 ${ }^{1,2}$. Many other names have been applied to this syndrome including congenital hypoplastic anemia, chronic congenital aregenerative hypoplastic anemia and erythrogenesis imperfecta. There are approximately 400 cases reported in the literature. Of the reported cases, male and female are equally affected. Most cases are Caucasian, but blacks, oriental and Indians have been reported.
\end{abstract}

Approximately 30 to $40 \%$ patients have congenital anomalies, most common finding is short stature followed by deformities in craniofacial region and upper limb, mostly involving thumb $b^{3,4}$. The inheritance of Diamond Blackfan anemia is not clear, 10 to $15 \%$ of cases are familial ${ }^{5}$. Diamond Blackfan anemia (DBA) belongs to the emerging class of ribosomal disorder, it links to mutations in the ribosomal protein genes rps19, rps 24, and rps $17^{6}$. To date there are no definite tests to diagnose DBA. Prenatal diagnosis is currently only possible if there is mutation affecting Rps19. The diagnostic criteria include ${ }^{7}$ :

- Normochromic, often macrocytic anemia with retculocytopenia developing early in childhood.

- Bone marrow with normal cellularity and usually a deficiency of red cell precursors.

- Normal or slightly decreased leukocyte count.

- Normal or often increased platelet count.

Complete blood count and films shows a normochromic anemia but normal white cells and platelet count. The red cell MCV is often high. Bone marrow confirms aplasia. The enzyme adenosine deaminase (eADA) in the red blood cell is usually raised. Radiological manifestations are those of the thumb malformation which is usually triphalangeal, and may be bifurcated, hypoplastic or subluxed.

About $30 \%$ of patient with Diamond-Blackfan anemia respond to oral prednisolon. High dose methyl prednisolon sometimes work. Cyclosporine alone with steroid also works in some cases ${ }^{8}$. Blood transfusion is only treatment who does not respond to steroid. Bone marrow transplantation ${ }^{9,10}$ and haematopoietic stem cell transplantation ${ }^{11}$ are definitive mode of treatment.

At least five patients have been reported in India ${ }^{12}$. Considering the rarity of the disease, we decided to report the case.

\section{Case Report}

A 4 months old male child of nonconsanguineous parents hailing from Tongi presented with gradual pallor for last 2 months along with cough and cold. He was a full term baby delivered by cesarean section with birth weight of $2.7 \mathrm{~kg}$. He developed convulsion on $3^{\text {rd }}$ day of life and convulsion occur once only, all other

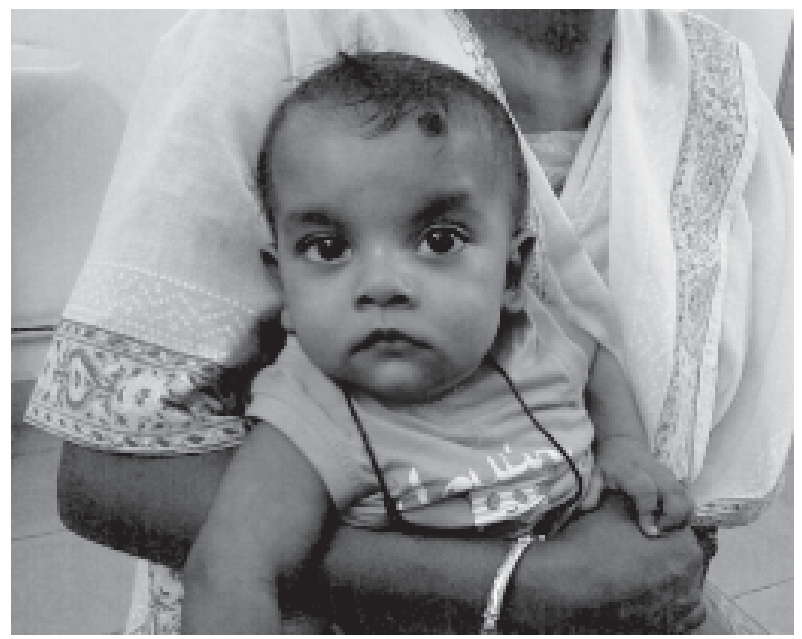

Fig.-1: Baby boy having no dysmorphic facies

\footnotetext{
1. Assistant Professor, Paediatrics, Uttara Adhunik Medical College Hospital, Dhaka, Uttara, Bangladesh.

2. Associate Professor of Paediatrics, Uttara Adhunik Medical College Hospital, Uttara, Dhaka, Bangladesh

3 Assistant Professor of Haematology, BSMMU, Dhaka, Bangladesh

4. Assistant Registrar of Paediatrics, Uttara Adhunik Medical College Hospital, Uttara, Dhaka, Bangladesh

5. Assistant Registrar of Paediatrics, Uttara Adhunik Medical College Hospital, Uttara, Dhaka, Bangladesh Correspondence: Dr. Sabina Sultana
} 


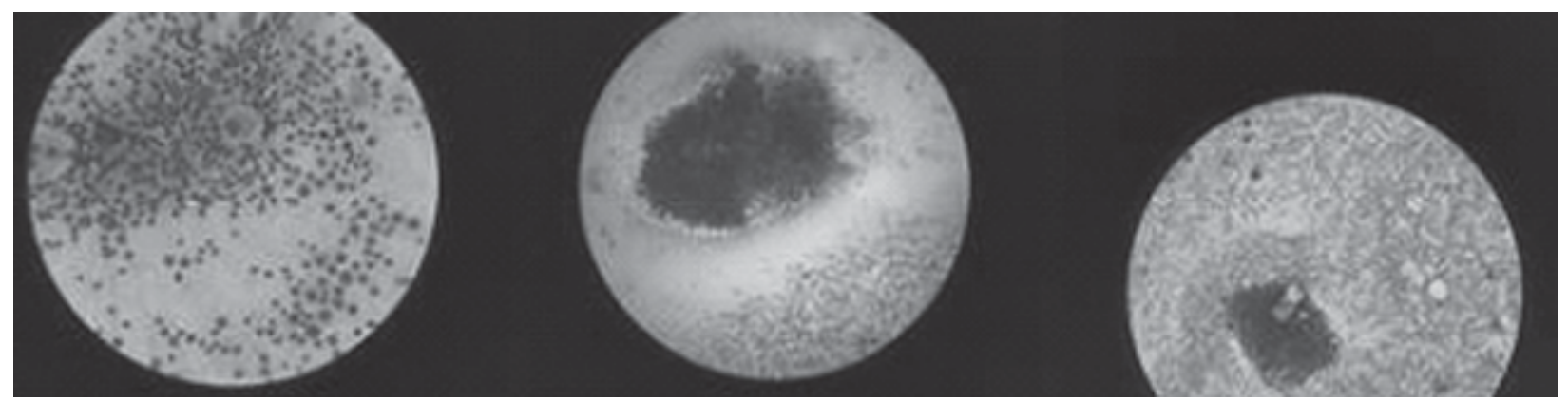

Fig.-2: Bone marrow slide of pure red cell aplasia (Diamond blackfan anemia)

investigation was normal except blood sugar level which was low. At one month of age the boy suffered from pneumonia. He was on formula milk along with breast milk. His milesstone of development was age appropriate. His mother was on regular antinatal checkup and did not have any significant illness during pregnancy and had no family history of similar illness.

On physical examination, baby was malnourished with weight $4 \mathrm{~kg}$ (WAZ-3.1 (SD) and length $56 \mathrm{~cm}$, OFC $38.5 \mathrm{~cm}$ (LAZ2.5SD). He had severe palor without any dysmorphic facie (Fig.-1) and had tachycardia and tachypnoea. There was no organomegaly.Investigation showed anemia (haemoglobin 3.9gmldl), with normal red cell morphology (Red cell count $01.10^{12} / \mathrm{L}, \mathrm{MCV}$ : 84.6fl MCH: $27.40 \mathrm{pg}, \mathrm{MCHC}: 32.30 \mathrm{gm} / \mathrm{dl})$. Normal white cell and platelet count ((TC: $4500 / \mathrm{mm}^{3}$, Neutrophil 14\% lymphocyte 50\%, Eosinophil 04\%, Monocyte 06\%, ESR:68, Platelet count: 5,10,000/ $\mathrm{mm}^{3}$ ). Reticulocyte count $0.2 \%, \mathrm{Hb}$ electrophoresis and TORCHS screening are normal. Serum Iron level is $210 \mathrm{mg} / \mathrm{dl}$. On bone marrow examination (Fig.-2), erythropoisis is depressed with reduction of red cell precursors, granulopoisis is hyperactive, myelocytes and megakaryocytes are increased.

Baby was managed with blood transfusion. Prednisolone was started with $2 \mathrm{mg} / \mathrm{kg} /$ day but after 6 week there was no improvement and hemoglobin was dropped again. Methyl prednisolone was started on a tapering dose and given 6 doses, followed by oral prednisolon, now the child is on fortnightly follow up and maintain $\mathrm{Hb}$ around $10 \mathrm{mg} / \mathrm{dl}$ for last two month.

\section{Discussion}

Diamond-Blackfan anemia is a rare etiology for congenital anemia ${ }^{12}$. But this diagnosis should be considered when hypoplastic anemia occurs in infancy. This disorder is very heterogeneous in character, only $10-20 \%$ cases; it is inherited as autosomal recessive manner ${ }^{5}$. Our patient also a child of nonconsanguinous patient. Recently being discovered that DBA is linked to mutation in the ribosomal protein gene rps19, rps24, and rps17. The missense mutations in DBA primarily attract the capacity of the protein to be incorporated into preribosome, thus blocking maturation of the pre- 40 s particles ${ }^{6}$.

The case reported here, diagnosed at 4 months of age, when he present with severe palor, but his neonatal period is not uneventful.

The diagnosis of DBA made most commonly in infancy. Twenty five present of reported infant were anemic at birth, $65 \%$ by 6 months, and $90 \%$ by one year. Rare cases were diagnosed between 2 and 6 year of age ${ }^{7}$.

The anemia of DBA is usually profound at the time of diagnosis. Hemoglobin level average $6.5 \mathrm{gm} / \mathrm{dl}$, in patients diagnosed in the first two months of life and $4 \mathrm{gm} / \mathrm{dl}$ in those diagnosed later. In our patient Hemoglobin level was $3.9 \mathrm{gm}$, at the age of 4 month.

The anemia is normocytic, but it is macrocytic in one third with reticulocyte counts are usually zero. White blood counts are normal or slightly decreased, while platelet counts are normal or increased ${ }^{7}$. Our patient have normocytic anemia with reticuloytc count $0.2 \%$, white blood cell count ate normal with increased platelet count. Bone marrow cellularity with erythroid hypoplassia in $90 \%$ of cases as well as our patient also has.

Our patient had no congenital anomalies, usually in 30-40\% patient with DBA anemia have congenital anomalies, particularly of the upper limb and craniofacial regions ${ }^{4}$.

Prednisolon is the initial treatment, the dose is $2 \mathrm{mg} /$ $\mathrm{kg}$, divided doses until $\mathrm{Hb}$ reaches $10 \mathrm{gm} / \mathrm{dl}$. Then the 
dose is tapered and treatment is given on alternate days. A few puzzling patients respond to corticosteroids initially, but then fail to maintain erythropoisis on doses that are less than toxic. Our patient does not respond oral prednisolon, but later on response to high dose methyl prednisolon $(30 \mathrm{mg} /$ $\mathrm{kg}$ ) for 4 day. Then $20 \mathrm{mg} / \mathrm{kg}$ for 3 days, later on methyl prednisolon is replaced by oral prednisolon (the pulse therapy could not complete). A low dose corticosteroid plus androgen occasionally useful. Recently cyclosporin Ain combination with prednisolon improves success rates and can be steroid sparing ${ }^{8}$. Interleukin 3 has been tried.

If all medication fails blood transfusion is only option. Regular blood transfusions lead to problems of iron overload. Bone marrow transplantation is only definitive treatment but it is not always successful. A recent study in Japan found an $85 \%$ success rate with haemotopoietic stem cell transplantation ${ }^{11}$.

Remission has occurred in approximately $17 \%$ of DBA patient reported by Diamond Blackfan Anemia Registry (DBAR). Remission occur following both steroid and/or transfusion therapy.

There is an increased risk of leukemia of these patient ${ }^{12}$. So life long follow up is necessary.

The reported mortality rate is approximately $15 \%$ although it is undoubtly higher. Most death was from complication of chronic transfusion, haemosiderosis, such as heart disease, pneumonia, infection. Our patient now on follow up, maintains $\mathrm{Hb}$ around $10 \mathrm{gm} /$ $\mathrm{dl}$, with oral prednisolon.

\section{Conclusion}

Early infantile anemia should be carefully investigated and close follow-up should be performed during the first few months of life, even if there is an obvious etiology.

\section{References}

1. Josephs HW. Anemia of infancy and early childhood. Medicine 1936; 15: 307-451.

2. Diamond LK, Blackfan KD. Hypoplastic anemia. Am J Dis Child 1938; 56: 464-67.
3. Alter BP. Childhood red cell aplasia. Am J Pediatr Hematol Onco 1979; 54: 263-67.

4. Alter BP. Thumbs and anemia. Pediatrics 1978; 62: 613-14.

5. Gazda HT, Sieff CA. Recent insights into the pathogenesis of Diamond-Blackfan anemia. $\mathrm{Br}$ J Haematol 2006; 31:243-52.

6. Gregory CA, Aguissa-Toure AH, Pin N, Legrand P. Molecular basis of Diamond-Blackfan anemia; structure and function analysis of RPSI9. Nudeic Acid Res 2007; 38: 5913-21.

7. Annotations, Red cell Aplasia in Children. Arch Dis Child. 1979; 54: 63-67.

8. El-Beshlawy A, Ibrahim Ly, Rizk S. Study of 22 Egyptian Patients with Diamond- Blackfan anemia, Corticosteroids, and Cyclosporin Therapy results. Pediatrics 2002; 110: e 44.

9. Iriondo A, Garijo J, Baro J. Complete recovery of hemopoiesis following bone marrow transplant in a patient with unresponsive congenital hypoplastic anemia (Blackfan- Diomond Syndrome). Blood 1984; 64: 348-51.

10. Roy V, Perez WS, Eapen M. Bone marrow transplantation for diamond-blackfan anemia. Biol Blood marrow Transplant 2005; 11: 600-08.

11. Ohga S, Mugishima H, Ohara A. DiamondBlackfan anemia in Japan: Clinical outcomes of prednisolone therapy and hematopoietic stem cell transplantation.; Int J Hematol 2004; 79: 2230.

12. Agarwal RK, Moudgil A, Pati H, Bagga A, Chowdhry VP, Saraya AK. Congenital pure red cell aplasia in northern India. J Pediatr1985; 52: 97-102.

13. Beauchamp Nicoud, Anne MD, Da costa Lydic. Proust Alexis. Rince et al. Postmortem Diagnosis of Diamond-Blackfan Anemia. J Ped Hem Onco 2004; 26: 847-48.

14. Krishnan EV, Gangsk WK. Congenital hypoplantic anemia terminating in acute promyelocytic leukaemia. Pediatrics 1978; 61: 898-901. 